\title{
Start Small and Build: How to Ease Into Flipping Your First Classes
}

\author{
Craig McBride \\ University of Washington Tacoma, United States
}

\begin{abstract}
This paper describes my experiences flipping my first few undergraduate mathematics and statistics courses with some advice for any fellow novice flippers. This paper discusses ways to start small and build up to a completely flipped class over the span of just a few terms with suggestions on what tools to use including software and hardware.
\end{abstract}

\section{Introduction}

In most traditional classroom settings, students listen to lectures in class while reading textbooks and working on assignments outside of class. By comparison, a flipped (backwards, inverted, or reverse) classroom is a form of teaching where students learn most or all of the content outside of the classroom, while classroom time is spent doing homework and group work with teachers providing guided instruction. The delivery of the content may vary, but most instructors use some form of video lecturing similar to the Khan Academy videos. Without the need for lectures each day, class time is freed up for hands-on work where teachers can better utilize their time providing more personalized instruction to students. Students learn by doing and asking questions while helping each other, which benefits both the advanced and less advanced learners.

In an ordinary class, students show up each day with a vast range of knowledge on the topic being discussed. In order to keep every student on track, teachers are often forced to begin teaching the material from the beginning. This leads to the more advanced students becoming bored and distracted. Additionally, material is either skipped or rushed through in order to make up for lost time. In an ideal setting, students would pre-read or at least skim through the material PRIOR to class so that the lesson could start more in the middle of the topic rather than having to review the most basic aspects. We've all tried to accomplish this by assigning readings in our books, and we've all experienced how few students pre-read anything (especially mathematics and science books.) By providing the material in video form or even something as simple as PowerPoint slides, students are far more likely to engage with the material. This leads to a much more narrow range of knowledge levels and abilities. So, when lecturing becomes necessary, it can be shorter and much more focused on only those topics that are still causing confusion for the students.

My reasoning behind trying the experiment of "flipping" my classes was to hopefully achieve three things. First, I was hoping to cover more material. Second, I was hoping to engage the students more in class by "lecturing" less. Third, I was hoping the students would have an enjoyable experience with mathematics because the vast majority of students were non-math/science majors and most had preconceived prejudices against math. I had read various articles [3] - [14] and heard speakers [1] \& [2] at the 2013 Joint Mathematics Meetings extoll the virtues of flipping classrooms and how much success they had seen from their trials. I always wanted to try it, but I just didn't have the time to create all of the videos and other materials that were (in my opinion) necessary to successfully flip a mathematics classroom, so I decided to start slowly and see what worked.

\section{How it all began}

My adventures with flipping began informally in the spring of 2013 while teaching at a small private liberal arts college in the Pacific Northwest area of the United States. It was during the fall semester that I began to look for a better way to teach the material. Part of my teaching load included two sections of Introduction to Applied Statistics. Classes were capped at 24 , and most students were liberal arts or other non-math/science majors in their first or second year. Each classroom had large chalkboards up front, individual student desk/chair combinations, a lectern podium with a computer, and an overhead projector with pull-down screen in the corner. Unfortunately, the department saddled me with one of the worst statistics texts I ever used, Moore's Introduction to the Practice of Statistics $\left(7^{\text {th }}\right)$. The content was okay, but the homework sets were abysmal. I desperately wanted to try a different book with my two sections of Statistics in the upcoming spring semester.

Since I was going to switch out the book, I felt it was a good time to try a different format too, because the current (more traditional) mode of instruction just wasn't working well. The students were doing adequately well with the material (some far better or worse than others), but it felt so lifeless. Even though we met four days a week (off on Wednesdays) 
during a 16-week semester, I still had to spend most of each 50-minute class period lecturing about material while students frantically took notes or just zoned out altogether. I would elicit laughs when I could and pry answers out of them as often as possible, but they never seemed fully engaged with the material. So, over the winter break, I decide to take the plunge and flip my Statistics classes.

\section{Starting small - no videos}

Wanting to try flipping, but not having time to create videos, I decided to start with PowerPoint slides and some other online materials instead. I had taught a few online Statistics courses previously with Triola's Elementary Statistics $\left(11^{\text {th }}\right)$, and I really liked the book, so I decided to adopt it for the spring classes. The book came with a fantastic set of multimedia materials including lecture slides created by the author/publisher, which helped greatly with front-end prep time. They were very thorough and covered all of the information from each chapter including most or all of the worked out examples. I was able to augment and edit the slides relatively easily, and within a few days I had a full set of very professional looking lecture slides.

That first try at flipping was an exciting experience. I was both scared and excited at the prospect of trying something new, and having to reevaluate everything I did in and out of the classroom raised my passion for teaching to a new level. I was excited and energized, and I think the students picked up on it. The class was flipped from the beginning of the term utilizing PowerPoint slides as the major mode of delivery for lecture material. Whenever possible, I would supplement the slides with applets, online resources, and video lessons. Most resources (including videos) were linked to the book or found on the internet rather than having to be created by me. As before, classes met every day except Wednesday, and students were expected to read through the PowerPoint slides on their own or in groups outside of class before we began that lesson in class. The slides were thorough enough that students no longer NEEDED to read their books, but some students would skim through the book as they went through the slides. Class time was devoted to answering some guided questions, homework questions, and working through examples of the techniques discussed in the PowerPoint slides in groups using real world data. Additionally, I would use class time to present "mini-lectures" (10-20 minutes) whenever necessary.

A typical class consisted of five minutes asking probing questions about the out-of-class material to gauge if they "got it" or not, always being prepared to lecture on every topic if needed. The probing questions were intended to get them talking about the major concepts they were supposed to grasp from the slides. They were open-ended questions instead of things that elicited a numerical answer. For instance, Instead of asking them to compute the probability of a sample statistic, I would ask them to describe in their own words what the Central Limit Theorem meant or have them summarize the concept of a hypothesis test in their own words. Then, we would spend five to ten minutes doing a few examples (1020 if it seemed like the class needed more guided practice). The remaining 25-40 minutes was spent working in groups on more examples - slightly less if a "mini-lecture" was needed. Just because you are giving them the material outside of class doesn't mean you still don't have to prep a lecture each day! Especially if you are only using slides and other nonvideo materials, it is likely that a lot of your students will still need some form of lecture reinforcement in class. Instead of having to lecture from scratch and cover everything from the basics up, you do a shortened more targeted "mini-lecture" that begins more in the middle of the topic and can go deeper into the topic.

The need for fewer and shorter lectures allowed me time each day to move around the room utilizing differentiated teaching while working with students and groups one-on-one answering questions and providing formative feedback. I was then able to use probing questions to get students to describe their thought processes and statistical reasoning skills. Probing questions often started with "why" or "how" instead of "what". They were already figuring out "what" the solution was in their groups, so I would ask them to explain "why" we used one formula over another or "how" this particular question differed from another and what that meant about how we would solve other similar questions. By requiring them to continuously explain their results verbally to me in class, they were forced to understand their results rather than just being able to get a number from a calculator. Being able to ask them these types of questions one-on-one meant the quieter students could still learn through explaining their thought processes without having to speak up in front of the entire class. Quiz and test questions also required students to "explain and interpret" their results using complete sentences, so everything built on the verbal explanations they practiced in class. Group work was given almost every day and it usually consisted of a few questions that modeled the material being discussed with current real-world data and contexts. At the end of each chapter, we would also use the author's "Active Learning" question slides. These consisted of multiple choice questions covering both 
topics and computational-type questions from the entire chapter. The students would get into groups and discuss and then come to a consensus on each question. Each group would turn in a master response sheet (with each student keeping a copy of their answers themselves), and then we would reveal the answers and discuss as a group. A few extra credit points were given to the teams with the highest scores. It was a nice way to review and summarize all of the major topics in each chapter before moving on to the next lesson.

\section{Next step - other peoples' videos}

After successfully flipping my first classes, I decided to try it again in a completely different setting to see if it could still be successful. The next fall, I began teaching at a large state university satellite campus that caters to non-traditional students. Classes typically met twice a week for 125 minutes each day during a ten week quarter term. Classes were capped at 30 , and per usual, the majority of students were first or second year students. The classroom was similarly equipped as my previous school with the exception of movable two-person desks instead of individual chair/desk units. I still had ample board space and a pull-down screen for the overhead projector that was controlled by the lectern computer. In contrast to my previous school, more of these students were pursuing science-related degrees, and many were working full-time and/or classified as military or "nontraditional" students. The student body is similar to what you would encounter teaching at a Community or Technical College.

My first assignment in the autumn 2013 term was two back-to-back Calculus 1 classes, and the thought of having to actually "lecture" for nearly four hours straight each day made my throat hurt. During the successful trials of the previous year, I purchased a Wacom Bamboo Capture (CTH-670) tablet for $\$ 300$ (comparable ones are now under $\$ 50$ ), a high-quality USB headset microphone (\$40), and Camtasia recording software. Camtasia is screen-capturing software that will record your whole computer screen or a portion of it with audio and even video input from a webcam. If you have ever seen videos from Khan Academy, they use Camtasia. It is rather expensive at $\$ 300$, and there are less-expensive options like Panopto, Tegrity, Doceri and others. There are even free options like Jing and CamStudio, but I found Camtasia to be worth the money. Besides, my school had a license, so I got it for free!

During that first semester of Statistics flipping, I had started small by merely posting video solutions to homework questions, then graduated to making short instructional videos for some of the more confusing subjects in the Statistics class. However, time constraints did not allow me to create videos for my Calculus class so I had to rely on other resources. We used the 7th edition of Stewart's Calculus Early Transcendentals, which doesn't come with any PowerPoint slides or other multimedia supplements. Since I didn't have time to create my own slides or videos, I turned to YouTube for help. I found so many excellent videos on every subject we were going to cover that I was able to compile a list of five or more video recommendations for each section. I created a simple Google Doc (Figure 1) with the title of each chapter and hyperlinks to each video. I also include a short title and the author of each video. This version includes links to my own videos (listed first, of course), but the original version only had videos from other people.

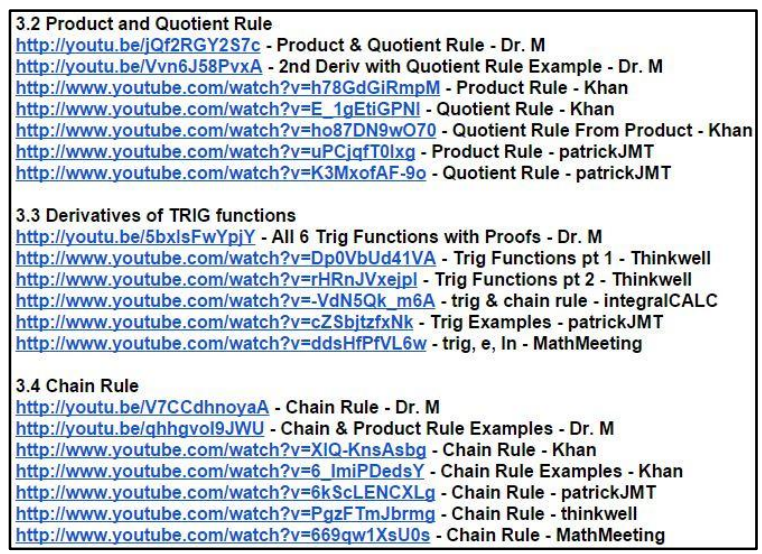

Figure 1. Google Doc list of videos

I tried to make it as simple as possible for my students to use the tools by giving them one place to find all of the links sorted by book chapter and topic. I would find different authors for each topic while using videos from the same people repeatedly whenever they turned out to be particularly good teachers. By listing the author's name for each video and offering multiple choices for videos for each topic, students could watch videos presented by the people they tended to like the best or avoid the people they didn't like. Since they were only asked to watch a minimum of ONE video per topic, they had the ability to pick and choose who they liked best. When I ended up teaching Calculus 1 again in the following spring 2014 term, I merely added my own video links to the list. I still gave them the entire list of videos so they could watch multiple videos if they chose.

I modeled my overall class structure after the Statistics class with more time allocated to each class phase. Instead of reading PowerPoint slides, students were now expected to watch at least one video and 
begin working on their homework BEFORE each class. We began each day with around 30 minutes of answering homework questions and discussing the major topics of the sections. As before, I would always have a lecture prepared and I would give a mini-lecture on the material if it seemed like the class was still struggling with the major concepts. I could also touch on the concepts as we went through their homework questions. After most of their questions were answered, they would spend 30-45 minutes taking their daily Concept Check (CC) on the same material we just reinforced. Because we only met twice per week for 10 weeks, we often had to cover two or even three sections per class. The last 45-60 minutes were spent working on homework or a worksheet of sample questions. I encouraged them to work in groups, but some students preferred to work on their own. Homework and quizzes were done online using the publisher's LMS (WebAssign) while all exams were given in class on paper.

\subsection{Introducing Formative Assessments}

The CC's were something new I introduced this term. The philosophy behind the $\mathrm{CC}$ is three-fold. First, I wanted a quick and easy way to get some formative assessment of the students' progress and knowledge on the topics each day. Second, I wanted to provide the students with daily feedback so they could themselves assess how well they understood each topic. Third, I wanted to boost their confidence and reduce test anxiety by giving them a few questions that they should be able to do with moderate success. As long as they watched the video and started the homework and then paid attention during the question and answer session, there was no reason why they couldn't get an $80 \%$ or better on each CC. I would still throw in some more challenging questions here and there to push them and keep the more advanced students active, but mostly they were middle-of-the-road questions that they could use as a study guide. If they got a question wrong, they knew they needed to spend more time on that concept, and I was there to give them immediate feedback as to what specifically they were doing incorrectly. I have found that this form of instant feedback is invaluable and one of the reasons why the online homework systems can be so beneficial to learning.

Each CC contained two to five questions modeled after the homework, and they were intended to highlight the major topics and techniques of each section covered that day. I call them Concept Checks instead of quizzes because it tends to lower stress levels and levels of test anxiety in the students. The CC's contained simple questions like using the product rule to take the derivative of some functions or using the limit laws to evaluate a set of limits. Students were allowed to use their books, notes, and formula sheets on the CCs, so care was taken to make sure that each question was not part of their actual homework assignment nor was it any odd numbered questions without first changing numbers and details. Students were given roughly 30 minutes to finish each $\mathrm{CC}$ and they brought their answers to me as they finished so I could quickly grade each one and offer instant formative assessment and feedback. Grading them as they finish saves a lot of time. If it appeared that a majority were struggling with the same question, we would discuss that question as a class and a few similar examples after the CC's were all done. I would also point them to similar homework questions to practice.

Although I did not have any control group or experience teaching the course the "traditional" way in this new setting, I was able to compare my student's results with other sections of Calculus 1 offered at the same school over the previous few years. My pass rate was higher, and the overall average grade was also higher. Additionally, student attitudes seemed better than what my colleagues reported in their traditional classes. End of term student evaluations revealed that most favored the new format, and my classes for the next term quickly amassed long wait lists.

\section{Fully flipped with my own videos}

With the time afforded me over the winter break, I was able to take flipping to the next level with my next three classes. In the winter 2014 term, I had one section of Introductory Statistics and two sections of Precalculus. Along with Calculus 1, these are the three worst courses in our department in terms of failure rates. Precalculus is particularly bad with drop/fail rates routinely at $20-35 \%$. The main problem with all three courses (and especially Precalculus) is the sheer volume of material that needs to be covered in such a short amount of time. Being on a quarter system means we already have to cover a 16-week semester's worth of material in only 10 weeks. To make matters even worse, our classes normally meet only twice per week. So, instead of meeting 4-5 times per week for 50 minutes, we meet twice per week for 125 minutes. In order to cover the same amount of material in this short timeframe, we have to cover two or even three sections every day.

Since I already had so many statistics materials from my previous school, I was able to start creating more videos for both classes. We were using a different book at this school, Elementary Statistics, 8th edition by Neil A. Weiss, but since I had created 
my videos on TOPICS rather than on CHAPTERS, I could still use most of them. By now, I had gotten pretty good at creating lecture videos using Camtasia, PowerPoint slides, a Wacom tablet, various software, and online tools. Texas Instruments provides a free TI-83 graphing calculator emulator, so I am able to bring it up on screen and show students how to input the data and conduct the necessary analyses using their calculators as I talk about various topics. Additionally, there are free online statistical sites like Vassarstats.net that are easy to use as well. Most Pearson textbooks come with free access to their fee-based service, StatCrunch. StatCrunch is similar to SPSS in that it employs a simple menu-based interface along with a spreadsheet for the data. It is powerful enough for an introductory course and easy enough to use that anybody can learn to use it quickly.

Recently, I have switched from StatCrunch to Excel for all statistical analyses. The analysis tool pack add-on in Excel is robust enough to perform all analyses needed in an introductory level course. Additionally, I feel that Excel is a useful tool for my students to learn because it may help them in other classes as well as their future careers. Since Camtasia records everything on your screen, you can use any programs or online tools you want and the students can see how to use them as you work through a question or demonstrate a technique.

Luckily for me, the Precalculus book, Precalculus a Unit Circle Approach by Ratti \& McWaters came with a great set of PowerPoint slides that I was able to edit and augment easily as I had done so with the original Statistics slides. By keeping my original Statistics lectures organized by topic rather than by section or chapter, I was able to re-use them even with a completely different textbook. That little tip alone saves me the time and hassle of having to recreate and re-record everything whenever I change textbooks. With most of the Statistics work done already, I could devote enough time to completing my entire library of Statistics videos while building from scratch a set of Precalculus videos.

One of the nice features of Camtasia is how seamlessly it integrates with YouTube. I am able to edit and then upload my videos directly to my own YouTube channel where my students (and anyone else) can watch them. Having your own YouTube channel is much better than using the servers that are traditionally tied to programs like Panopto or Tegrity. Recently, our school switched from Tegrity to Panopto. Even though the IT department migrated all of our Tegrity videos over to the Panopto servers, it still meant that every video hyperlink in a syllabus or on a website no longer worked. All of my videos are on my YouTube channel (DrCraigMcBridePhD) and those links will never change, so I never have to worry about updating hyperlinks.

Rather than requiring my students to hunt around through hundreds of videos on my channel, I create simple Google Docs (Figure 2) for each class with hyperlinks to each video placed in a schedule. I can then publish this schedule to Canvas where my students are able to click through to my videos directly from our Canvas class site. You can accomplish similar results with Moodle, Blackboard, and most other course management systems that your school might use. Using Google docs allows me to make edits and changes to the "live" document without having to worry about updating it on Canvas as well. Since the file is embedded, it gets updated automatically. It is similar to how a webpage is updated, and yet we still get to it through the same URL address.

\begin{tabular}{|c|c|c|c|c|}
\hline $\begin{array}{r}\text { Course } \\
\text { https://docs.google.com/document/d1N9mu81 }\end{array}$ & $\begin{array}{l}\text { e Calend } \\
\text { ifovBor }\end{array}$ & culrc ZNoVu & 00 M4SwfXiCa6w & \\
\hline Videos to watch BEFORE Class & DATE & $\begin{array}{l}\text { Sections } \\
\text { Covered }\end{array}$ & Items Due & Due \\
\hline $\begin{array}{l}\text { Real Numbers, } \\
\text { Polvnomiles of Exponents \& Order of Operations, }\end{array}$ & Mar 31 & A1 \& A2 & A1 \& A2 & Apr 2 \\
\hline Rational Expressions, Roots \& Radicals & Apr 2 & A3 \& A4 & $\begin{array}{l}\text { A3 \& A4, Quiz 1, } \\
\text { Fractions1 }\end{array}$ & Apr 6 \\
\hline Geometry, Solving Equations & Apr 7 & A5\&A6 & A5 \& A6 & Apr 9 \\
\hline Inequalities, Complex Numbers & Apr 9 & A7 \& A8 & $\begin{array}{l}\text { A7 \& A8, Quiz } 2 \text { \& } \\
\text { Fractions } 2\end{array}$ & Apr 13 \\
\hline Graphs of Equations, Lines & Apr14 & $1.1 \& 1.2$ & $1.1 \& 1.2$ & Apr 16 \\
\hline Functions & Apr 16 & & 1.3, Quiz 3, Fractions 3 & Apr 20 \\
\hline Library of Functions, Transformations of Functions & Apr 21 & $1.4 \& 1.5$ & $1.4 \& 1.5$ & Apr 23 \\
\hline Composite Functions, Inverse Functions & Apr 23 & $1.6 \& 1.7$ & $\begin{array}{l}1.6 \& 1.7, \text { Quiz 4, } \\
\text { Fractions } 4\end{array}$ & Apr 27 \\
\hline \begin{tabular}{|l} 
Ouadratic Functions, Polmomial Functions \\
.
\end{tabular} & Apr 28 & $2.1 \& 2.2$ & 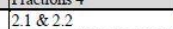 & Apr 30 \\
\hline Rational Functions, Variation & Apr 30 & $2.5 \& 2.6$ & 2.5, Quiz 5, MIIITERM & I May 4 \\
\hline Exponential Functions, Logarithmic Functions & May 5 & $3.1 \& 3.2$ & $3.1 \& 3.2$ & May 7 \\
\hline $\begin{array}{l}\text { Rules of Logarithms, } \\
\text { Exponential \& Logarithmic Equations } \\
\end{array}$ & May 7 & $3.3 \& 3.4$ & $\begin{array}{l}\text { 3.3 \& 3.4, Quiz 6, } \\
\text { Fractions } 5\end{array}$ & May 11 \\
\hline \begin{tabular}{|l} 
Angles and Their Measure. \\
Unit Cincle \& Trio Functions \\
\end{tabular} & May 12 & $4.1 \& 4.2$ & $4.1 \& 4.2$ & May 14 \\
\hline $\begin{array}{l}\text { Unit Circle \& Trig Functions } \\
\text { Trigonometric Functions of Angles } \\
\end{array}$ & May 14 & 4.3 & 4.3 \& Quiz 7 & May 18 \\
\hline Graphs of Sine \& Cosine. & May 19 & $4.4 \& 4.5$ & $4.4 \& 4.5$ & May 21 \\
\hline \begin{tabular}{|l} 
Graphs of Other Trig Functions \\
Inverse Trig Functions \\
\end{tabular} & May 21 & 4.6 & $4.6 \&$ Quiz 8 & May 25 \\
\hline MEMORIAL DAY - NO CLASS!!!! & May 26 & & & \\
\hline $\begin{array}{l}\text { Triq Identities \& Eovutions, Sum \& Difference Fornulas } \\
\text { Double-Angle \& Half-Angle Formulas }\end{array}$ & May 28 & $\begin{array}{l}5.1,5.3 \& \\
5.4\end{array}$ & $5.1,5.3 \& 5.4$, Quiz 9 & Jun 1 \\
\hline Right Triangle Trigonometry, Law of Sines & Jun 2 & $6.1 \& 6.2$ & $6.1 \& 6.2$ & $\operatorname{Jun} 4$ \\
\hline Law of Cosines & $\operatorname{Tun} 4$ & 6.3 & $6.3 \&$ Quiz 10 & $\operatorname{Tun} 8$ \\
\hline & $J \operatorname{lag} \theta$ & & & \\
\hline 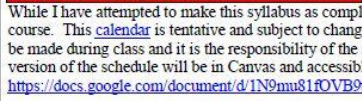 & $\begin{array}{l}\text { ge at th } \\
\text { studen } \\
\text { ble dire } \\
\text { guxulre }\end{array}$ & at this ? & $\begin{array}{l}\text { the instructor. Announcer } \\
\text { ed if class is missed. A "1 } \\
\text { M4SwrXiCa6wsoYI }\end{array}$ & $\begin{array}{l}\text { ghout the } \\
\text { nents will } \\
\text { ive" }\end{array}$ \\
\hline
\end{tabular}

\section{Figure 2. Google Doc schedule with links}

Since my Precalculus videos were a "work in progress" as the term progressed, this auto-updating feature was essential. As long as I stayed a week or two ahead of my students, I could take my time and create good lecture videos and videos of sample problems with solutions. Then I could post the new links to the Google doc as we went along through the term and the new hyperlinks would show up in Canvas as well. The students would continue working through the material without missing a beat. It also allowed me the time to answer homework questions by posting a quick video solution rather than trying to type out a solution over email, which we all know is VERY difficult with mathematics symbols and functions. 
Whenever I would solve a homework question, I would post the video and a PowerPoint slide with the worked-out problem. I created a new slide for each question, and I kept them in order by chapter and question number. This was the only thing that I kept tied directly to the text, but the videos were still labeled by topic instead of question number. I then created a Google Slides file and would copy and paste each new slide to it at the end of the day. Again, I could embed it straight into Canvas, so the students could access it at any time to see if a solution had been posted for a question. Then, they could look at the slide and watch the video. If they still had questions, they were encouraged to post them to the forums and then other students could post solutions for extra credit. They could also email me directly if they were uncomfortable asking the class, but students rarely opted to email me.

As I continue to teach each subject repeatedly, the slides become a great resource for students. Since the online homework systems generate the same questions with different numbers, students get guidance without getting the answers in most cases. I would bring my Wacom tablet to class and use it to create new slides (and videos) as I answered homework questions in class each day. Sometimes students would still want to see how to solve a question with their specific numbers, but I would always try to use a different set of numbers first. If they still had trouble, I would use their numbers or go through it with them one-on-one. I don't mind giving away a free homework point here or there because I believe the main goal of homework should be to reinforce the skills rather than assess points.

\section{Students' attitudes and success}

By the end of the winter term (only my third term trying any form of flipping), flipping had become easy. The students were used to the format and I was able to make videos quickly and easily. Before class each day, I would log into the LMS to see how they were doing. It was so shocking to see how many students had regularly done most if not ALL of their homework before we had even begun to discuss it in class. The students loved the format, and they were thriving in this setting.

At the end of the term, only four of 60 Precalculus students failed mainly because all four had just stopped coming to class or doing any work. All 30 of the Statistics students passed, and the class averages for all three were significantly better than the other sections on campus. Even though my grading schemes are very similar to the other instructors, I began to worry that maybe I was somehow making it too easy to get a good grade in my class because these kinds of results seemed way too good to be true. Currently, we are in the process of tracking my students to see how they perform in subsequent courses to see if their improved performances continue or not.

The end of course evaluations and my own personal surveys consistently showed a significant improvement in student attitudes. Although some students did not like the experience, most stated they enjoyed the experience during both informal and formal surveys. I collected anonymous survey responses both during and after the term. These results along with unsolicited responses both verbally and via email suggest that most students enjoyed the class and many of the non-science majors stated learning more and enjoying the class more than any other mathematics class.

Because this was a new experience for both me and my students, I would regularly gauge their attitudes by asking how they were doing with everything. The student responses have been consistently positive including two teaching award nominations. Students have begun to ask what other courses utilize this mode of instruction. Flipping has gained so much popularity and shown such promising results that many of my colleagues have begun using my videos with their classes or are beginning to flip their own classes.

In addition to better grades and attitudes, flipping also allowed me to cover far more material than my colleagues, but I worried that the pace was still too fast for the students. In Statistics, other classes stopped at simple linear regression, but we continued on and covered multiple regression, non-linear regression, logistic regression, chi-square goodnessof-fit, chi-square contingency tables, one-way ANOVA, and two-way ANOVA. I was afraid we were going too fast, so I would ask for student feedback informally as well as through anonymous surveys. Surveys suggest the students did not feel as if we were going too fast. 23 students responded, and most felt the pace was okay with only one student feeling we were going way too fast. The survey results along with my own informal surveying of asking for students' opinions during class and in office hours suggests that the majority felt the pace was okay. I even had some students come into class midway through the term saying that friends of theirs in other classes were several weeks behind us in the material. I asked if they felt we were going too fast, and they all said "no" and they were more surprised at how "slow" the other classes were going.

In the spring 2014 term I taught two sections of Calculus 1 and one section of Precalculus. I was only supposed to teach one section of Calculus, but after more than 38 students had requested to be waitlisted 
in my first section of Calculus, we had to offer the second section. The courses went well and the student attitudes seemed to be so much better than in other classes. Demand for my classes continued to grow and students regularly asked the administration what classes I was teaching next term or when I would be teaching a certain subject. I am hoping that future analyses of their performances will show that they are in fact learning the material better and thus performing better in future mathematics and science classes.

\section{Some helpful suggestions}

My advice to anyone considering flipping their class (especially a mathematics or statistics class) is to go for it, but don't be afraid to take baby steps. I understand first-hand how daunting it can feel to think about having to create all of the videos and other supplemental materials, but you don't have to do it all at once. In fact, you don't have to do any of it yourself if you can find the appropriate materials from other people. Let me start by saying my website https://sites.google.com/site/drcraigmcbridephd/ is always available and my email mcbridec@uw.edu is always on, so please contact me with any questions.

\subsection{Start small by using other peoples' stuff}

There is no reason why we all have to continuously reinvent the wheel ourselves when we can use each other's videos and resources. All of my videos and thousands of other quality videos are free to use and available on YouTube. You just have to take the time to watch them to see that they cover the correct things. In all of my classes, I create a discussion board where students can post links to videos or resources that they find and I usually award small amounts of extra credit to anyone who finds really good ones. Crowd source your videos. Your students already spend thousands of hours each year watching videos online, so let the experts help you find good ones.

Look for resources from your textbook, the publisher, other books, and colleagues. Most texts come with Powerpoints and other resources like links to applets etc. Most items are free to use with no copyright issues, and those that are copyright protected can either be allowed for use by the publisher if you ask or just use them as inspiration for your own items.

\subsection{Invest in the correct tools}

The Wacom Bamboo pad is now under $\$ 40$ for the wired USB version, but I would recommend spending the \$20 extra for the wireless version. It allows you to get out from behind the podium and roam around the classroom while still writing on the overhead projector. Buy a comfortable high-quality microphone. Logitech has nice models like the H390 under $\$ 40$. You can use an iPad or tablet to present material in class and write on top of slides, OneNote, or other backgrounds using a stylus pen.

Programs like Splashtop and Doceri allow you to remotely control and mirror your lectern computer onto your iPad or tablet for around \$30. Most schools have site licenses for Camtasia, Tegrity, Panopto, or similar lecture capturing software. Camtasia is expensive at $\$ 300$, but I feel its ease of use and overall superior functionality make it worth the investment. Jing is available free, but it only records in five minute increments. There are other free or low-cost solutions out there as well.

Online learning management systems like WebAssign, MyMathLab, MyStatsLab, and others may seem expensive for your students with access codes costing anywhere from $\$ 65$ to $\$ 125$, but when you consider that they all come with a free copy of the eBook and most students are fine using it, it can actually end up costing them less than the price of a new book. The online books also have the added bonus of being searchable and coming with multimedia embedded in it. So, as students read through the chapter, they can click on an icon and launch a video or an applet that will help them investigate the concept. Many of the homework problems offer video or written solutions and tutorials as well. In my opinion, the ability to practice problems over and over while getting targeted feedback is invaluable for student learning and makes these services worth the money. However, there are several great websites with free applets and materials that can still offer some benefit to your students, so just start looking.

\subsection{Create a YouTube channel}

I highly recommend you create a YouTube channel and put all of your videos there for two reasons. One, it allows the entire world to see them and benefit from them (as long as you set the privacy settings to public). Two, you can take them with you easily if you ever change schools. I have recently gone through the very tedious and confusing process of renaming my YouTube channel to something that makes more sense (DrCraigMcBridePhD), so my students can find me more easily. I would suggest that when you create your YouTube channel that you pick a logical name to begin with to save you the headache of changing it later. 
I have heard some teachers voice concern that their schools may not like them putting videos out there for the world to see or that they might try to claim ownership of their videos. I think that as long as you are creating them at home on your own time using your own equipment, they shouldn't have any legal right to what you create nor be able to tell you not to do it. However, you might want to check first just to be sure.

\subsection{Make videos on topics and not chapters}

I now have a complete set of videos for Statistics, Precalculus, and Calculus 1. I created all of the PowerPoint slides and videos based on topics rather than book chapters so that they will remain relevant and useful regardless of textbook changes. This means that some chapters may require multiple videos while others only one. I have heard some experienced flippers say that videos need to be kept short (under 5-10 minutes), but my own experience is that students prefer less videos even if that means that each one is longer. Because technology makes it so easy for them skip around in a video, I feel that the psychological impact of seeing a list of ten videos to watch is far worse than having to watch one 30-minute long video.

\subsection{Daily formative assessment is key}

Make sure and require attendance or give daily quizzes. I tried flipping an eight week evening class once without having the quizzes, and as soon as the students figured out the videos were all online, they stopped coming to class and just treated it like an online class instead. Out of 15 students only 3-4 would show up each night. Other teachers have expressed similar concerns or have seen similar problems where students end up treating the course like an online course since they can get all of the materials outside of the classroom. So, you must provide incentives for coming to class. They don't realize how much they learn from being in the classroom with other students asking questions and discussing the topics, so do whatever is necessary to make sure they attend class.

My daily concept checks have made a huge improvement on student grades. Giving students immediate feedback on what they are doing is invaluable! Keeping the CC's low-stakes and allowing students to improve their scores by correcting mistakes means that the stress-levels are low, but the learning levels are high. Students can see what topics I feel are important and what topics they still don't understand. This helps guide their studies in a more productive direction

\subsection{Final words of wisdom}

Flipping has been a wonderful experience for me. I have seen students that traditionally struggle with math leave my classes smiling and excited to learn. I have at times struggled with technology and made mistakes. I have learned a lot, and hopefully your entry into flipping will be even smoother with some of my suggestions.

Simple tips like formatting all of your PowerPoint slides to 13.3 " by 7.5 " (1280 x 720) makes the video fit perfectly on YouTube without any cropping. Using PowerPoint slides instead of OneNote or Smoothdraw keeps you focused and forces you to stay organized. Learn to love the pause button when making videos. You don't have to do everything in one take, and using the pause button while you change programs or open things helps minimize dead-air. Keep a log next to you as you record and write down the timestamp of coughs and other things you will want to remove during the editing process. Don't forget to use the cursor or a pointer tool when you want to draw attention to something because the students can't see where you are pointing your finger in a video! Use colors and don't be afraid to create things before you even push record. Lastly, relax and have fun with it - your students will enjoy the ride so much more if they know you are having fun too.

Flipping can seem like a lot of work up front and it is if you start from scratch and try to do it all at once, but you don't have to do that. Start slow - flip just one chapter or one topic or one lesson. Use other materials and videos and let other people do the heavy lifting for you until you feel comfortable enough making your own materials. As educators we all know that an ideal student would read or at least skim through the chapter material PRIOR to class, so that we could just hit the highlights and then have more time to work examples and dive deeper into the material. As educators we also know that students RARELY read the book (especially mathematics books). Flipping gets them to gain the same level of insight they would from reading the book by giving them the material in a mode they are more accustomed to using. PowerPoints, videos, applets, and other online tools are things they see and use every day and are thus far more willing to spend time utilizing. I have seen an amazing transformation in my students over a short period of time, and you too will be amazed at how much better your students do and how much more engaged they are in class. 


\section{References}

[1] Abbasian, R. O., \& Sieben, J.T. (2013, January 9). A Brief tutorial on building a "flipped" classroom. Paper presented at the 2013 Joint Mathematics Meetings, San Diego, CA. Abstract retrieved from http://jointmathematics meetings.org/amsmtgs/2141_abstracts/1086-vf-2336.pdf

[2] Aragon, R. D., Brown, T., \& Bell, M. (2013, January 9). Flipping a college algebra classroom. Paper presented at the 2013 Joint Mathematics Meetings, San Diego, CA. Abstract retrieved from http://jointmathematicsmeetings .org/amsmtgs/2141_abstracts/1086-h1-406.pdf

[3] Baker, Celia. (2012, November 25). Flipped classrooms: Turning learning upside down: Trend of "flipping classrooms" helps teachers to personalize education. Deseret News. Retrieved from http://www.deseretnews .com/article/765616415/Flipped-classrooms-Turninglearning-upside-down.html?pg=all

[4] Bergmann, J. \& Sams, A. (2012). Flip Your Classroom: Reach Every Student in Every Class Every Day. International Society for Technology in Education.

[5] Berrett, D. (2012, February 19). How 'flipping' the classroom can improve the traditional lecture. The Chronicle of Higher Education. Retrieved from http://chronicle.com/article/How-Flipping-theClassroom/1 30857/

[6] Fulton, K. (2012, April). Inside the flipped classroom. The Journal. Retrieved from http://thejournal.com/articles/ 2012/04/11/the-flipped-classroom.aspx

[7] Gojak, L. (2012, October). To Flip or Not to Flip: That is Not the Question! National Council of Teachers of Mathematics. Retrieved from http://www.nctm.org/about/ content.aspx?id=34585

[8] Gorman, M. (2012, July 18). Flipping the classroom...a goldmine of research and resources keep you on your feet. Retrieved from http://21centuryedtech.wordpress.com/

[9] Green, G. (2012, July). The Flipped Classroom and School Approach: Clintondale High School. Presented at the annual Building Learning Communities Education Conference, Boston, MA. Retrieved from http://2012.blc conference.com/documents/flipped-classroom-schoolapproach.pdf

[10] King, J. (2011, September 29). Flipped instruction. Retrieved from: http://blogs.bcbe.org/blogit/2011/09/29/ flipped-instruction/

[11] November, A. \& Mull, B. (2012, March 29). Flipped learning: A response to five common criticisms. Retrieved from: http://novemberlearning.com/assets/flipped-learninga-response-to-five-common-criticisms.pdf
[12] Pfeiffer, K. (2012, February 17). The flipped classroom: Teaching and learning in the 21st century. Retrieved from: http://info.lecturetools.com/blog/?Tag= Flipped\%20Instruction

[13] Saltman, D. (2011, November/December). Flipping for beginners: Inside the new classroom craze. Retrieved from: http://hepg.org/hel/article/517

[14] Strayer, J. (2012). How learning in an inverted classroom influences cooperation, innovation and task Orientation. Learning Environments, 15(2), 171. 